\title{
Response to: Ranibizumab vs. pegaptanib: a cost-effectiveness study?
}

\author{
Luis Javier Hernández-Pastor
}

Received: 30 March 2010 / Accepted: 2 April 2010 /Published online: 27 April 2010

(C) Springer-Verlag 2010

We would like to thank Professor Wiwanitkit for the interesting comments on our paper [1].

First, it is true that our analysis is indeed a cost-utility analysis. Cost-utility analysis is an adaptation of costeffectiveness analysis [2]. Some authors use both terminologies but to be more precise we agree with Professor Wiwanitkit's clarification.

Regarding indirect costs, we acknowledge that not all indirect costs are included in our analysis. In the manuscript we highlighted some limitations such as recall bias, lack of data derived from nursing home patients, or indirect costs related to productivity of patients or family members. We believe, however, that had all the costs been included, the disease burden would increase, and a more favorable result for ranibizumab (i.e., a lower incremental cost-effectiveness ratio), would probably be obtained [1].

Professor Wiwanitkit mentions different costs between the present work [1] and a past work [3]. It is interesting to highlight that we adopted different perspectives in these studies. In the past study [3], a third-party payer perspective was chosen, and only direct costs from our hospital were taken into account. Our unit costs reflect those of a private hospital, so it is difficult to say that they are fully representative of other Spanish institutions. In the second study, we took a Spanish societal perspective and costs were taken from the cited source [4].

We believe that outcomes of both studies show consistency, being ranibizumab generally regarded as a non-cost-effective strategy when monthly dosed compared either to photodynamic therapy or pegaptanib. Ranibizumab may be cost-effective when dosed on a per-needed basis, although with a high level of uncertainty as reflected in the sensitivity analyses.

\section{References}

1. Hernández-Pastor LJ, Ortega A, García-Layana A, Giráldez J (2010) Cost-effectiveness of ranibizumab compared with pegaptanib in neovascular age-related macular degeneration. Graefes Arch Clin Exp Ophthalmol 248(4):467-476

2. Palmer S, Byford S, Raftery J (1999) Economics notes: types of economic evaluation. BMJ 318(7194):1349

3. Hernández-Pastor LJ, Ortega A, García-Layana A, Giráldez J (2008) Cost-effectiveness of ranibizumab compared with photodynamic treatment of neovascular age-related macular degeneration. Clin Ther 30(12):2436-2451

4. Cruess AF, Zlateva G, Xu X, Soubrane G, Pauleikhoff D, Lotery A, Mones J, Buggage R, Schaefer C, Knight T, Goss TF (2008) Economic burden of bilateral neovascular age-related macular degeneration: multi-country observational study. Pharmacoeconomics 26:57-73

\footnotetext{
L. J. Hernández-Pastor $(\bowtie)$

Pharmacy Department, Clínica Universitaria,

Universidad de Navarra,

AV/Pio XII, 36. 31.008,

Pamplona, Navarra, Spain

e-mail: luisjaher@unav.es
} 